\title{
Evaluation model of construction site personnel management based on FAHP
}

\author{
LiWen Cui ${ }^{1, a}$, YongFeng Chen ${ }^{1, b}$ \\ ${ }^{1}$ School of Management,Xi'an university of architecture and technology, Xi'an 710055,China

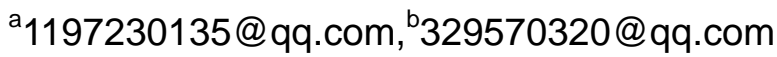

Keywords: Construction site; Analytic hierarchy process; Fuzzy analytic hierarchy process

\begin{abstract}
Construction site personnel management is an important part of project management, which is an important factor in the progress of the project. According to the characteristics of the construction site, this paper establishes the evaluation index system of the construction site personnel management. Secondly, according to the problem of the test process of analytic hierarchy process(AHP) is relatively complex,the paper makes full use of fuzzy analytic hierarchy process (FAHP), and combines with the actual project construction site, and puts forward the evaluation model of personnel management.
\end{abstract}

\section{Introduction}

At present, many scholars have done a lot of research on the construction site management, Liu Qingjuan $^{[1]}$ has established a scientific and reasonable evaluation system of construction site progress control, and combined with fuzzy evaluation method, In a certain sense, man is the key to the success or failure of the project, all of which are created by people who will be made of materials. Only with a creative, disciplined construction team to complete a high quality project. In this paper, the idea of fuzzy analytic hierarchy process is applied to the management of construction site, the same is to improve the construction quality, speed up the construction progress, only to solve the problem, it is to solve the fundamental problem.

\section{Establishment of comprehensive evaluation index system}

Due to the continuous expansion of the scale of the construction site, the factors affecting the construction site management are also increasing, so the enterprise in the construction site management is more complicated.In general, according to the wishes of people and the multi-objective decision-making,should repeat a comprehensive analysis to determine the overall goal and sub goals, to handle the target for indicators, formed index system. In the middle of the construction site personnel management, overall goal for managers, two factors affecting personnel management are the quality of employees and the organization structure, which is the intermediate STRATON target. Then analyzes two intermediate STRATON target, determine the impact of each factor, according to the science, rationality and applicability of established following the construction site personnel management evaluation index system.

Table 1 Construction site personnel management evaluation index system

\begin{tabular}{cc}
\hline First level indicator/A & Second level indicator/B \\
\hline & Employee motivation (B1) \\
Staff quality (A1) & Condition (B2) \\
& Mental state (B3) \\
& Skill level (B4) \\
& Education level (B5) \\
\hline Management mode (A2) & Organization structure (B6) \\
& Rules and regulations (B7) \\
& Rewards and punishment measures (B8)
\end{tabular}




\section{Fuzzy Analytic Hierarchy Process (FAHP)}

Analytic hierarchy process (AHP) is a combination of qualitative analysis and quantitative analysis.The key of AHP is to establish judgment matrix, and to judge whether the matrix is reasonable or not directly affects the results of AHP, so the following problems arise in the process of real application:

(1) In the establishment of a judgment matrix, the neglect of the artificial ambiguity.

(2) The test procedure is relatively complex: when the order number $n$ of the matrix is relatively large, the workload of the maximum eigenvalue is relatively large, which requires some help from the software.

(3) Judging whether the matrix has the same test criteria: the lack of scientific basis.Based on the above problems, the concept of fuzzy analytic hierarchy process is put forward by Zhang Jijun ${ }^{[5]}$.

\subsection{Fuzzy consistent matrix correlation concept}

Definition 1 Set matrix $R=\left(r_{i j}\right)_{n \times n}$, if meet:

$$
0 \leq r_{i j} \leq 1,(i=1,2 \cdots n, j=1,2 \cdots n), R \text { is called the fuzzy matrix. }
$$

Definition 2 The fuzzy matrix $R=\left(r_{i j}\right)_{n \times n}$, if meet:

$$
r_{i j}+r_{j i}=1,(i=1,2 \cdots n, j=1,2 \cdots n) \text {, then } R \text { is the fuzzy complementary matrix. }
$$

Definition 3 If the fuzzy complementary matrix $R=\left(r_{i j}\right)_{n \times n}$ is defined $\forall i, j, k$

$$
r_{i j}=r_{i k}-r_{j k}+0.5 \text {, then } R \text { is the fuzzy consistent matrix. }
$$

\subsection{Fuzzy analytic hierarchy process (FAHP) to establish fuzzy complementary matrix}

First establish the hierarchy analysis index system, establish the relationship between the levels, and then according to the important degree of the elements, the fuzzy complementary matrix, the importance of the scale as shown in table 2.

Table 2 The importance of scale of fuzzy complementary matrix

\begin{tabular}{cc}
\hline Importance scale & Meaning \\
0.5 & $i$ and $j$ are same important \\
0.6 & $i$ indicators is slightly important than $j$ \\
0.7 & $i$ indicators is obviously important than $j$ \\
0.8 & $i$ indicators is more important than $j$ \\
0.9 & $i$ indicators is extremely important than $j$
\end{tabular}

$0.4 、 0.3 、 0.2 、 0.1$

Anti comparison

\subsection{The weight of each index is determined by the fuzzy complementary matrix}

Theorem 1 By the importance of the above scale to get fuzzy complementary matrix $R=\left(r_{i j}\right)_{n \times n}$, the weight values between the index elements $\omega_{1}, \omega_{2}, \omega_{3} \cdots \omega_{n}$, then there are the following relations:

$$
r_{i j}=0.5+a\left(\omega_{i}-\omega_{j}\right), i, j=1,2,3 \cdots n
$$

Theorem 2 If the fuzzy consistent matrix $R=\left(r_{i j}\right)_{n \times n}$ is obtained by the sum of the rows, then the matrix is still fuzzy consistent with the following mathematical transformation.

$$
a_{i j}=\frac{a_{i}-a_{j}}{2(n-1)}+0.5
$$

Theorem 3 The above matrix $\left(a_{i j}\right)_{n \times n}$, for the order of the vector $\omega=\left(\omega_{1}, \omega_{2} \cdots \omega_{n}\right)^{T}$

$$
\omega_{i}=\frac{\sum_{j=1}^{n} a_{i j}+\frac{n}{2}-1}{n(n-1)}, i=1,2,3 \cdots n
$$




\section{Application examples}

\subsection{S project construction site introduction}

$\mathrm{S}$ project is located in Xi'an high tech Zone, with a total construction area of about 22.67 million square meters, 5A class office, five-star hotels and upscale business as a whole, of which 45 storey headquarters building, about 217.95 meters, five-star hotel design level 35, building height of about 7 meters, the total amount of steel 3 million tons is until now in Northwest China's first all steel structure high-rise projects. Developers neglect the importance of the construction site management, leading to the construction process, in order to ease the construction pressure, better for the management of personnel, timely discovery of the management of the problem, using the fuzzy analytic hierarchy process to evaluate its field personnel management.

\subsection{Establish fuzzy consistent matrix}

By using the importance of Table 2, the importance of the index layer is compared, and the fuzzy consistent matrix is established, and the weight of each index is calculated according to the theorem 3 and theorem 3.1 .

Table 3 Fuzzy complementary matrix and weight of first level index

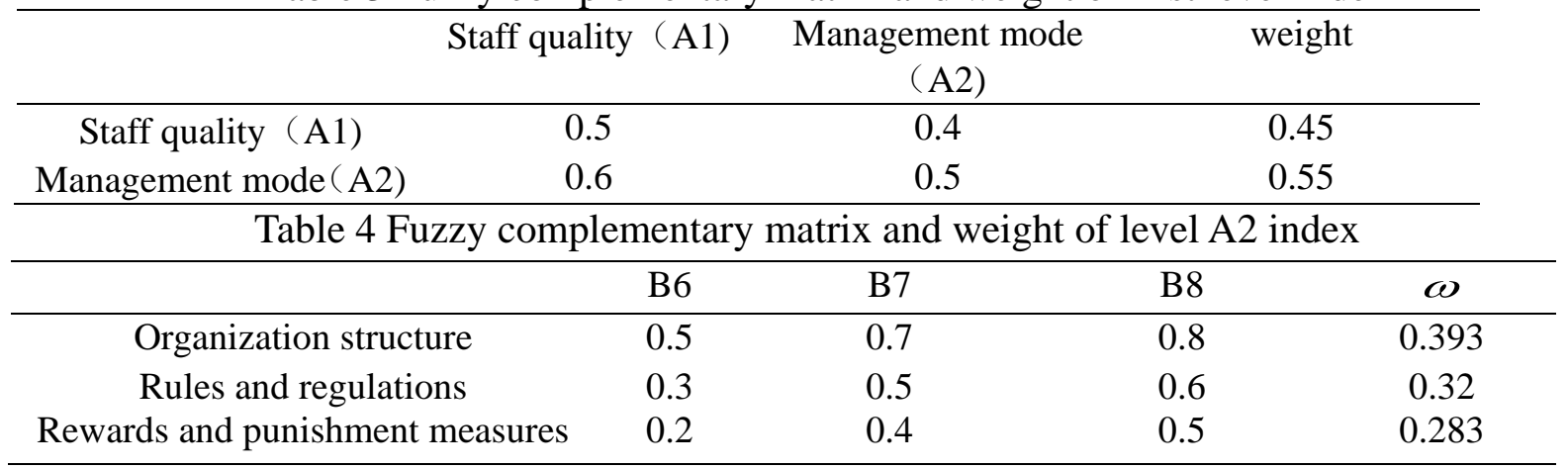

Table 5 Fuzzy complementary matrix and weight of level A1 index

\begin{tabular}{ccccccc}
\hline & B1 & B2 & B3 & B4 & B5 & $\omega$ \\
\hline Employee motivation & 0.5 & 0.4 & 0.7 & 0.3 & 0.6 & 0.2 \\
Condition & 0.6 & 0.5 & 0.8 & 0.4 & 0.7 & 0.215 \\
Mental state & 0.3 & 0.2 & 0.5 & 0.1 & 0.4 & 0.169 \\
Skill level & 0.7 & 0.6 & 0.9 & 0.5 & 0.8 & 0.231 \\
Education level & 0.4 & 0.3 & 0.6 & 0.2 & 0.5 & 0.184 \\
\hline
\end{tabular}

Through the above definition 3,the consistency check of fuzzy complementary matrix at all levels of index is found to satisfy the above definition, and the matrix is the consistency matrix.

Table 6 Complex weight of every index

\begin{tabular}{cccc}
\hline Index layer & index & Weight & $\begin{array}{c}\text { Comprehensive } \\
\text { weight }\end{array}$ \\
\hline First level indicator & Staff quality & 0.45 & 0.45 \\
A & Management mode & 0.55 & 0.55 \\
\hline & Employee motivation & 0.2 & 0.09 \\
Second level indicator & Condition & 0.215 & 0.097 \\
A1 & Mental state & 0.169 & 0.076 \\
& Skill level & 0.231 & 0.104 \\
Second level indicator & Education level & 0.184 & 0.083 \\
A2 & Organization structure & 0.393 & 0.216 \\
& Rules and regulations & 0.32 & 0.176 \\
& Rewards and & 0.283 & 0.156 \\
\hline
\end{tabular}




\subsection{Establish fuzzy relational matrix}

In order to obtain the relatively reliable results, the questionnaire of this evaluation is given to the relevant persons in the industry and the project. Through the evaluation of the above set, the membership function of each index is calculated:

Table 7 Membership matrix of comment set

\begin{tabular}{cccccc}
\hline & \multicolumn{5}{c}{ Evaluation grade } \\
\cline { 2 - 6 } Index & good & fine & general & poor & bad \\
\hline Employee motivation & 0 & 0.108 & 0.321 & 0.482 & 0.089 \\
Condition & 0 & 0.201 & 0.257 & 0.485 & 0.057 \\
Mental state & 0 & 0.126 & 0.317 & 0.425 & 0.132 \\
Skill level & 0 & 0.214 & 0.283 & 0.451 & 0.052 \\
Education level & 0 & 0.113 & 0.356 & 0.436 & 0.095 \\
Organization structure & 0 & 0.124 & 0.324 & 0.472 & 0.08 \\
Rules and regulations & 0 & 0.135 & 0.386 & 0.441 & 0.038 \\
Rewards punishment & 0 & 0.105 & 0.362 & 0.452 & 0.081 \\
\hline
\end{tabular}

\subsection{Fuzzy comprehensive evaluation}

According to the membership matrix and the weight of each index, the fuzzy relation matrix is established

$$
\begin{aligned}
& C_{1}=\omega_{1} V_{1}=(0,0.156,0.304,0.457,0.082) \\
& C_{2}=\omega_{2} V_{2}=(0,0.122,0.353,0.455,0.067)
\end{aligned}
$$

Namely fuzzy relational matrix $C=\left(\begin{array}{l}C_{1} \\ C_{2}\end{array}\right)=\left(\begin{array}{c}\omega_{1} V_{1} \\ \omega_{2} V_{2}\end{array}\right)=\left(\begin{array}{l}0,0.156,0.304,0.457,0.082 \\ 0,0.122,0.353,0.455,0.067\end{array}\right)$

The fuzzy comprehensive evaluation result is obtained by combining the weights of the first grade index: $C=(0,0.137,0.331,0.456,0.074)$.

\subsection{Evaluation results analysis}

Through the results of the above fuzzy comprehensive evaluation, we can see that the focus of the evaluation of the poor, the proportion of 0.456, you can determine the existing problems of the project site staff management. According to the comprehensive weight of the indicators in table 4.4 can be seen, the weight of the two indicators in the organization structure of 0.176 , the weight of the rules and regulations, the weight of 0.156 , so the project should pay more attention to the establishment of the organization structure, strengthening the management of the construction site personnel management model proposed new initiatives.

\section{Summary}

(1) The Fuzzy-AHP evaluation model of the construction site personnel management is established. The influence factors of the construction site personnel management are qualitatively and quantitatively analyzed.

(2) Using the fuzzy analytic hierarchy process and fuzzy comprehensive evaluation method to establish the evaluation model, the fuzzy nature of the decision making problem is considered, and the fuzzy complementary matrix is used to simplify the procedure of the consistency.

\section{References}

[1] Liu Qingjuan, Fan Yanyan. Evaluation model based on Fuzzy-AHP for construction progress control [J].Engineering Management Journal, (2012)No.6,p. 62-65.

[2] Chen Xueming, Xu Qicheng, Yu Ying. Fuzzy comprehensive evaluation model of building construction site safety [J]. Building safety, (2012)No.10, p.4-8.

[3] Zhu Mingming. Risk assessment of engineering projects based on fuzzy analytic hierarchy process [J]. Technology management research, (2010)No.20,p.214-217.

[4] Lan Jibin, Xu Yang, Huo Liangan, Liu Jiazhong. Fuzzy analytic hierarchy process weight study 
[J]. System engineering theory and practice, (2006)No.9, p.107-112.

[5] Zhang Jijun. Fuzzy analytic hierarchy process (FAHP) [J]. Fuzzy systems and mathematics, (2000)No.2, p.80-86.

[6] $\mathrm{Xu} \mathrm{Zeshui.} \mathrm{An} \mathrm{algorithm} \mathrm{for} \mathrm{fuzzy} \mathrm{complementary} \mathrm{judgment} \mathrm{matrix} \mathrm{sort} \mathrm{[J].} \mathrm{Systems}$ engineering journal, (2001)No.4,p.311-314.

[7] Li Hongyan, Chen Ming, Wang Tiening. The practice and recognition of the nonlinear membership function in fuzzy comprehensive evaluation [J]. Mathematics, (2006)No.9,p.125-127. 